\title{
Impact of race on short-term outcomes of patients undergoing combined coronary artery bypass grafting and mitral valve repair
}

\author{
Christina M. Vassileva, MD, Steve Markwell, MA, Theresa Boley, MSN, and Stephen Hazelrigg, MD, \\ Springfield, Ill
}

Race has been previously identified as a risk factor for adverse outcomes after coronary artery bypass grafting $(\mathrm{CABG}) .{ }^{1,2}$ Racial disparities with respect to combined valve and coronary surgery have received little attention. An ongoing study by the Cardiothoracic Trials Network is currently randomizing patients with moderate mitral regurgitation in the setting of CABG to concomitant mitral annuloplasty. Accordingly, the number of concomitant mitral annuloplasty procedures in the setting of CABG may increase as results from this study become available. The purpose of our investigation was to examine whether any racial differences exist with respect to hospital mortality and short-term outcomes in the subset of patients undergoing combined $\mathrm{CABG}$ and mitral valve annuloplasty.

\section{PATIENTS AND METHODS}

The study protocol was approved by the institutional review board. The 2005-2007 Nationwide Inpatient Sample (NIS) database was searched to identify patients who underwent combined CABG and mitral valve annuloplasty using the International Classification of Diseases, Ninth Edition, Clinical Modification (ICD-9-CM) procedure codes 35.33 and 36.10 to 36.19. Patients less than 30 years of age were excluded. Patients were also excluded if they had other valvular repair or replacement, congenital mitral valve disease, closed heart valvuloplasty, excision of aneurysm of heart, partial ventriculectomy, replacement of thoracic aorta, aortic fenestration procedure, previous cardiac surgery, and missing race information. Whites and non-whites were compared with respect to baseline characteristics (age, gender, income level, rural-urban residency, admission status, Charlson comorbidity index, and primary payer) and additional procedures during the hospital stay (number of CABG grafts, left internal thoracic artery use, Maze, intra-aortic balloon pump placement, and pacemaker insertion). Concomitant procedures, as well as complications, were identified by examining the procedure and diagnostic codes provided for each record in the NIS, which includes up to 15 procedure and 15 diagnostic codes according to the ICD-9-CM. The primary outcomes of interest were in-hospital mortality, length of stay (LOS), and disposition status. Statistical analyses included $\chi^{2}$ and $t$ tests for univariate comparisons and logistic regression for adjusted odds ratios. All analyses were performed using SAS version 9.1 (SAS Institute, Inc, Cary, NC) to perform the appropriate weighting to reflect the stratified sampling scheme used in the NIS.

\footnotetext{
From the Department of Cardiothoracic Surgery, Southern Illinois University, Springfield, Ill.

Disclosures: Authors have nothing to disclose with regard to commercial support.

Received for publication July 1, 2010; revisions received Nov 22, 2010; accepted for publication Dec 16, 2010.

Address for reprints: Christina M. Vassileva, MD, Southern Illinois University, Department of Cardiothoracic Surgery, 701N First St, Rm D319 PO box 19638, Springfield, IL 62794-9638 (E-mail: cvassileva@siumed.edu).

J Thorac Cardiovasc Surg 2011;141:845-6

$0022-5223 / \$ 36.00$

Copyright (c) 2011 by The American Association for Thoracic Surgery

doi:10.1016/j.jtcvs.2010.12.019
}

\section{RESULTS}

Results are depicted in Table 1. Non-whites comprised $20.5 \%(883 / 4299)$ of the study population. The majority of non-whites were African American (36.2\%, 319/883) and Hispanic $(32.0 \%, 282 / 883)$. Non-whites were younger, less affluent, more likely to be receiving Medicaid, and more often came from urban locations $(P<.01)$. The 2 groups did not differ with respect to admission status and Charlson comorbidity index. Significantly greater proportion of whites had a concomitant Maze procedure compared with non-whites $(17.9 \%$ vs $7.8 \% ; P<.01)$. There was no difference between the 2 groups with respect to number of CABG grafts, left internal thoracic artery use, intraaortic balloon pump placement, and pacemaker insertion. The 2 groups were similar with respect to postoperative neurologic, renal, and respiratory complications. Nonwhites had a longer mean LOS (19.4 vs 15.0 days; $P=.04)$ as well as higher proportion $(62.4 \%)$ at or above the median LOS of 12 days as compared with whites $(51.2 \% ; P=.0019)$. After adjustment for Charlson comorbidity index, age, urban-rural residency, payer status, income, and admission type, there was no difference between whites and non-whites with respect to in-hospital mortality $(P=.60)$ and discharge to home $(P=.35)$, whereas the racial disparity with respect to LOS persisted. Non-whites were more than twice as likely to have LOS of 12 days or more (odds ratio $=2.27 ; 95 \%$ confidence intervals, $1.51-3.40 ; P<.01)$.

\section{DISCUSSION}

Significant racial variation exists in the baseline characteristics of patients undergoing $\mathrm{CABG} / \mathrm{mitral}$ valve annuloplasty. Non-white patients are younger, less affluent, more often on Medicaid, and more often come from urban locations.

The Charlson comorbidity index was used for risk adjustment between whites and non-whites to avoid the limitation of missing comorbidity data. ${ }^{3}$ This index has been validated for use with large administrative databases. ${ }^{4}$ Similar Charlson comorbidity index for the 2 groups despite the younger age of the non-whites may reflect higher prevalence of comorbid conditions, an accelerated disease course in the non-white population, or lack of access to preventive health care/risk modifications strategies.

The finding that non-whites underwent concomitant Maze procedure much less frequently was intriguing. Non-whites had a diagnostic code for atrial fibrillation less 
TABLE 1. Race comparison of patients undergoing CABG/mitral annuloplasty (2005-2007 NIS database)

\begin{tabular}{|c|c|c|c|}
\hline & Non-white & White & $P$ value \\
\hline No. of patients $(\%)$ & $883(20.5)$ & $3416(79.5)$ & \\
\hline $\begin{array}{l}\text { Age: mean, median } \\
\text { (interquartile range) }\end{array}$ & $64.9,66(57-74)$ & $69.1,71(63-77)$ & ).0001 \\
\hline Age $\geq 70 y$ & $38.6 \%$ & $53.6 \%$ & .0001 \\
\hline Female & $41.0 \%$ & $37.2 \%$ & .3110 \\
\hline Urban & $93.9 \%$ & $80.4 \%$ & .0001 \\
\hline Medicare & $49.0 \%$ & $65.8 \%$ & .0001 \\
\hline Medicaid & $18.5 \%$ & $2.2 \%$ & .0001 \\
\hline \multicolumn{4}{|l|}{ Income } \\
\hline First quartile & $32.3 \%$ & $20.1 \%$ & .0031 \\
\hline Second quartile & $20.6 \%$ & $26.1 \%$ & \\
\hline Third quartile & $20.8 \%$ & $29.1 \%$ & \\
\hline Fourth quartile & $26.4 \%$ & $24.6 \%$ & \\
\hline \multicolumn{4}{|l|}{ Admission status } \\
\hline Elective & $36.5 \%$ & $40.0 \%$ & .4582 \\
\hline Urgent/emergency & $63.5 \%$ & $60.0 \%$ & \\
\hline $\begin{array}{l}\text { Charlson index: mean, } \\
\text { median (interquartile } \\
\text { range) }\end{array}$ & $2.04,2(1-3)$ & $2.06,2(1-3)$ & .8265 \\
\hline \multicolumn{4}{|l|}{ Concomitant procedures } \\
\hline Maze & $7.8 \%$ & $17.9 \%$ & .0011 \\
\hline Balloon pump & $22.0 \%$ & $19.0 \%$ & .4565 \\
\hline Pacemaker & $11.7 \%$ & $11.2 \%$ & .8798 \\
\hline \multicolumn{4}{|l|}{ Complications } \\
\hline Neurologic & $4.64 \%$ & $3.02 \%$ & .2649 \\
\hline Respiratory & $9.12 \%$ & $5.44 \%$ & .1104 \\
\hline Renal & $5.52 \%$ & $4.40 \%$ & .9937 \\
\hline $\begin{array}{l}\text { Length of stay: mean, } \\
\text { median (interquartile } \\
\text { range) }\end{array}$ & $19.4,15(8-21)$ & $15.0,12(8-17)$ & .0473 \\
\hline Length of stay $\geq 12$ days & $62.4 \%$ & $51.2 \%$ & .0019 \\
\hline In-hospital death & $6.4 \%$ & $5.3 \%$ & .5164 \\
\hline $\begin{array}{l}\text { Routine/home health care } \\
\text { disposition }\end{array}$ & $72.2 \%$ & $67.3 \%$ & .2143 \\
\hline
\end{tabular}

frequently than whites, but this differences did not reach statistical significance $(40.4 \%$ vs $48.1 \% ; P=.0772)$. Unfortunately, within the NIS database it was not possible to determine whether atrial fibrillation was a preoperative condition or a postoperative complication, limiting our ability to draw a definite conclusion of whether this reflects lesser incidence of preoperative atrial fibrillation in nonwhites requiring $\mathrm{CABG} / \mathrm{mitral}$ annuloplasty. Others have reported higher prevalence of atrial fibrillation in whites compared with non-whites. ${ }^{5}$ Hospital characteristics including available resources may be another important factor to consider. Within our study population, $99 \%$ of patients received treatment in urban as opposed to rural hospitals. Furthermore, there was no difference with respect to race in the proportion of patients who received treatment in teaching hospitals $(66.4 \%$ of non-whites vs $65.1 \%$ of whites; $P=.8355$ ). In addition, teaching and nonteaching hospitals were similar with respect to the proportion of patients receiving concomitant Maze procedures $(14.9 \%$ vs $17.6 \% ; P=.4059)$. Alternatively, individual surgeon skills or physician treatment bias with respect to race may be responsible for this finding. Non-whites were much more frequently on Medicaid, and it is possible that atrial fibrillation surgery was not performed because of lack of insurance reimbursement. Further studies may be warranted to investigate the use of the Maze procedure with respect to race and/or insurance type.

Although in-hospital mortality for patients undergoing combined $\mathrm{CABG} / \mathrm{mitral}$ annuloplasty was not influenced by race, non-whites had a more protracted hospital course despite younger age and similar Charlson comorbidity index compared with whites. This may be related to various socioeconomic factors and may be an important area to address in further efforts to decrease hospital costs.

Our study has several limitations. The NIS is a stratified probability sample of state inpatient databases including data on roughly $20 \%$ of hospital admissions in the United States. Therefore, to minimize sampling error, our data were weighted to make them more applicable to the entire inpatient population. The purpose of administrative databases is to gather data for billing purposes and can be limited by erroneous coding. The NIS database only contains the initial hospitalization information and therefore follow-up after discharge is not available. However, the NIS is the largest all-payer database in the United States, and some of its limitations are offset by large patient volumes, hard clinical end points, and the opportunity to explore real world community data, making our findings widely applicable across hospitals in the United States.

\section{References}

1. Cooper WA, Thourani VH, Guyton RA, Kilgo P, Lattouf OM, Chen EP, et al. Racial disparity persists after on-pump and off-pump coronary artery bypass grafting. Circulation. 2009;120(11 Suppl):S59-64.

2. Hartz RS, Rao AV, Plomondon ME, Grover FL, Shroyer AL. Effects of race, with or without gender, on operative mortality after coronary artery bypass grafting: a study using The Society of Thoracic Surgeons National Database. Ann Thorac Surg. 2001;71:512-20.

3. Deyo RA, Cherkin DC, Ciol MA. Adapting a clinical comorbidity index for use with ICD-9-CM administrative databases. J Clin Epidemiol. 1992;45: 613-9.

4. D'Hoore W, Bouckaert A, Tilquin C. Practical considerations on the use of the Charlson comorbidity index with administrative data bases. J Clin Epidemiol. 1996;49:1429-33.

5. Marcus GM, Olgin JE, Whooley M, Vittinghoff E, Stone KL, Mehra R, et al. Racial differences in atrial fibrillation prevalence and left atrial size. Am J Med. 2010;123:375.e1-7. 